\title{
Hypoglycemic Effect of Intestinally Administered Monosaccharide-Modified Insulin Derivatives in Rats
}

\author{
Makoto Haga, ${ }^{*, a}$ Katsumi Saito, ${ }^{a, 1)}$ Takahiro Shimaya, ${ }^{a}$ Yukiko Maezawa, ${ }^{a, 2)}$ Yuriko Kato $^{a}$ and Sung Wan Kim ${ }^{b}$ \\ Faculty of Pharmaceutical Sciences, Science University of Tokyo, ${ }^{a} 12$ Ichigaya Funagawara-machi, Shinjuku-ku, Tokyo 162, Japan and Department of \\ Pharmaceutics, University of Utah, ${ }^{b}$ Salt Lake City, UT 84112, U.S.A. Received November 22, 1989
}

The effect of the modification of insulin (INS) with $p$-succinylamidophenyl (SA)- $\alpha$-D-glucopyranoside (SAPG), SA- $\alpha$-D-mannopyranoside and SA- $\alpha$-L-arabinopyranoside on the enzymatic degradation and the hypoglycemic effect in rats was studied. When SAPG-INS was administered intraintestinally in the absence of bile and pancreatic juice, blood glucose level decreased to $56 \%$ of initial value. Other monosaccharide derivatives were less effective than SAPG-INS. The digestion of monosaccharide derivatives by pepsin and chymotrypsin indicated that the resistance of insulin to enzymatic degradation was increased by its modification with monosaccharide. One possibility for the hypoglycemic effect of SAPG-INS could be the increased resistance of insulin to enzymatic degradation as a result of its modification with monosaccharide.

Keywords insulin derivative; monosaccharide modification; hypoglycemic effect; intestinal absorption

Since the regular injection of insulin is troublesome to diabetics, many studies have been made to develop an oral or nonparenteral route. ${ }^{3-9)}$ Orally administered insulin is inactivated by digestion in the gastrointestinal tract and has low enterocyte permeability.

The use of various detergents in altering intestinal permeability has resulted in the promotive absorption of intact insulin. ${ }^{10,11)}$ A remarkable promotive effect of lipid-surfactant mixed micelles on the small intestinal absorption of macromolecules in rats has been reported. ${ }^{12)}$ Protection of insulin from enzymatic degradation also produces a hypoglycemic effect. Fujii et al. ${ }^{13)}$ demonstrated that FK-448, a potent and specific inhibitor of chymotrypsin, reduced insulin digestion and promoted its intestinal absorption in rats and dogs. Protection of liposomal insulin from digestive enzymes was demonstrated by Weingarten et al. ${ }^{14)}$ Recently, azopolymer-coated orally administered insulin has been effectively used in rats by Safran et al. ${ }^{15}$ )

In an alternative approach, Jeong et $a l .{ }^{16)}$ and Sato et $a l .{ }^{17)}$ developed a self-regulating insulin delivery system based on the competitive binding of glucose and glycosylated insluin to concanavalin A. They synthesized several glycosylated insulins ${ }^{18)}$ and examined their bioactivity on blood glucose levels (BGLs) after intraperitoneal injection in rats. Seminoff et al. purified and separated a mixture of $p$-succinylamidophenyl- $\alpha$-D-glucopyranoside insulin (SAPG-INS), characterized four products, and evaluated the liver uptake and antigenicity of the SAPGINS derivatives. ${ }^{19,20)}$ However, they have not examined the intestinal absorption of the SAPG-INS derivatives.

In this study, we synthesized three monosaccharidemodified insulin derivatives, SAPG-INS, $p$-succinylamidophenyl- $\alpha$-D-mannopyranoside (SAPM-INS) and $p$-succinylamidophenyl- $\alpha$-L-arabinopyranoside (SAPA-INS), and examined their resistance to enzymatic degradation and their hypoglycemic effect in rats.

\section{Materials and Methods}

Materials $p$-Nitrophenyl- $\alpha$-D-glucopyranoside (NPG), $p$-nitrophenyl$\alpha$-D-mannopyranoside (NPM), $p$-nitrophenyl- $\alpha$-L-arabino-pyranoside (NPA), insulin from bovine pancreas (crystalline) were from Sigma Chemical Co. (St. Louis, MO, U.S.A.). Other reagents were obtained as follows: ammonium formate, palladium carbon (10\%), succinic anhydride, tri- $n$-butylamine, isobutylchloroformate, methyl- $\alpha$-D-mannoside, orcin, ninhydrin and anhydrous hydrindantin from Nacalai Tesque, Inc. (Kyoto,
Japan); Dowex 1-X8 (200-400 mesh) from Muromachi Kagaku Kogyo Co., Ltd. (Osaka, Japan); insulin Novo actrapid MC from Kodama Co., Ltd. (Osaka, Japan); Glucose test Wako from Wako Pure Chemical Ind. Ltd. (Osaka, Japan); Bio-rad protein assay from Bio-rad Laboratories (Richmond, CA, U.S.A.); insulin kit "Daiichi" S from Daiichi Radioisotope Laboratories (Tokyo, Japan). All other reagents were commercial products of high purity and all operations utilized freshly redistilled water. Organic solvents were freshly distilled as required.

Preparation and Purification of SAPG-INS, SAPM-INS and SAPAINS The synthesis of SAPG, SAPM and their coupling to insulin were performed according to the method of Kim et al. ${ }^{18)}$ Briefly, the nitrophenyl group on NPG was reduced to aminophenyl group, yielding $p$ aminophenyl- $\alpha$-D-glucopyranoside (APG). APG was then allowed to react with succinic anhydride, yielding SAPG. The carboxylic group on SAPG was finally coupled to the free amines of bovine insulin with the use of a mixed anhydride method. SAPM and SAPM-INS, SAPA and SAPA-INS were prepared using the same method described for SAPG. The yield and melting point of $p$-amidophenyl- $\alpha$ - $\mathrm{L}$-arabinopyranoside (APA) were $65 \%$ and $181-182^{\circ} \mathrm{C}$, respectively. SAPA-INS was prepared without affinity column chromatography.

In Vivo Experiments Male Wistar rats (body weight $200 \pm 20 \mathrm{~g}$ ) were fasted for $24 \mathrm{~h}$ and then lightly anesthetized with ether and fixed on their backs on a board. After $10 \mathrm{~min}$, Somnopently $(43 \mathrm{mg} / \mathrm{kg})$ was injected intraperitoneally. These treatments affected the BGL very little. The right jugular vein was cannulated with heparinized polyethylene tubing and the abdomen was opened by a median incision. The duodenal region before or after the bile duct junction and the ileo-cecal junction were incised. The small intestine was washed with $20 \mathrm{ml}$ of $0.0667 \mathrm{M}$ phosphate buffered saline (PBS, pH 7.4) and the PBS was then washed out with air. The duodenal region was cannulated with tubing and the ileo-cecal junction was ligated. When the duodenal region was cannulated after the bile duct junction, bile and pancreatic juice (b/pj) did not flow in the small intestine. The intestine was then replaced in the peritoneal cavity and the abdomen was closed. A solution of control Actrapid insulin or monosaccharidemodified bovine insulin derivatives $(4 \mathrm{ml}, 50 \mathrm{U} / \mathrm{kg})$ was administered via the duodenal cannula $1 \mathrm{~h}$ after the fixation of the rats. Blood samples ( $c a$. $400 \mu$ l) were withdrawn from the jugular vein cannula and collected in heparinized tubes. In some experiments blood was withdrawn via a pyloric vein cannula, which was advanced to the level of main portal vein.

Degradation of Monosaccharide-Modified Insulin Derivatives The resistance of monosaccharide-modified insulin derivatives to pepsin and chymotrypsin was investigated by use of the ninhydrin method. Ninhydrin reagent was prepared by dissolving $0.8 \mathrm{~g}$ ninhydrin and $0.12 \mathrm{~g}$ hydrindantin in $30 \mathrm{ml}$ of 2 -methoxy-ethanol with the addition of $10 \mathrm{ml}$ of $4 \mathrm{M}$ sodium acetate buffer ( $\mathrm{pH} 5.5$ ). The reagent was immediately transferred to a dark bottle, then stored at $4^{\circ} \mathrm{C}$ under nitrogen atmosphere. Chymotrypsin and pepsin were dissolved at the concentration of 3 or $25 \mathrm{U} / \mathrm{ml}$ in $0.2 \mathrm{M}$ PBS $(\mathrm{pH} 8.0)$ or $\mathrm{HCl}$ solution ( $\mathrm{pH} 2.5$ ), respectively. The insulin derivatives and native insulin were dissolved at the concentration of $0.5,0.667,1.0$ and $2.0 \mathrm{mg} / \mathrm{ml}$ into each enzyme solution and incubated at $37^{\circ} \mathrm{C}$. Fifty $\mu 1$ was sampled at $0,1,2,3$ and $5 \mathrm{~min}$ time and the reaction was stopped by the addition of ice cold distilled water. One $\mathrm{ml}$ of ninhydrin reagent was added to $1 \mathrm{ml}$ of the sample solution. The solution was kept in boiling 
water for $15 \mathrm{~min}$, then cooled. Absorbance was determined at $570 \mathrm{~nm}$. A glycine calibration curve $(0.0625-2.0 \mathrm{~mm})$ was made.

Determination of Insulin and Immunoreactivity of Insulin The protein assay of insulin for the estimation of the degree of substitution was made using a Bio-rad protein assay kit. The calibration curve was made by dissolving bovine crystalline insulin $(0-25 \mu \mathrm{g} / \mathrm{ml})$ in $0.05 \mathrm{M}$ glycine $-\mathrm{HC}$ buffer ( $\mathrm{pH}$ 2.6). The immunoreactivity and blood levels of insulin were determined with the use of insulin kit "Daiichi" $S$. Radioactivity was measured in an auto well gamma counter (Aloka, ARC-300). The calibration curve was made with the standard insulin solution $(0$ $240 \mu \mathrm{U} / \mathrm{ml}$ ) incorporated in the kit.

Determination of Sugar and Blood Glucose Level The saccharide moiety of glycosylated insulin was determined by the orcinol-sulfuric method of Voelter and Bauer ${ }^{21)}$ with some modification. Sulfuric acid $(0.5 \mathrm{ml})$ containing $1 \%$ orcinol was added to $0.5 \mathrm{ml}$ of the sample. The solution was mixed well, kept in boiling water for $5 \mathrm{~min}$, then cooled in cold water for $2 \mathrm{~min}$. Absorbance was determined at $420 \mathrm{~nm}$. The calibration curve was made with SAPG, SAPM and SAPA $(0-40 \mu \mathrm{g} / \mathrm{ml})$. Blood glucose was determined as follows. One $\mathrm{ml}$ of $5 \%$ trichloroacetic acid was added to the rat blood sample $(50 \mu \mathrm{l})$. The solution was mixed well, kept at room temperature for $5 \mathrm{~min}$, then centrifuged at $3000 \mathrm{rpm}$ for $5 \mathrm{~min}$ and the supernatant $(0.5 \mathrm{ml})$ was mixed with $2.5 \mathrm{ml}$ of the reagent (Glucose test, Wako). The solution was kept in boiling water for $8 \mathrm{~min}$, and then cooled in cold water for $3 \mathrm{~min}$. Absorbance was determined at $635 \mathrm{~nm}$ within $1 \mathrm{~h}$ with distilled water as reference. The glucose calibration curve ranged from 0.5 to $5 \mathrm{mg} / \mathrm{ml}$.

\section{Results and Discussion}

Characterization of Monosaccharide-Modified Insulin Derivatives The physical and spectroscopic properties of SAPG, SAPM and SAPA are presented in Table I. The mp of SAPM was not determined because of its noncrystalline form. It was estimated from the protein assay and sugar determination of glycosylated insulin that the average number of molecules of monosaccharide per molecule of insulin (SAPG, SAPM or SAPA/insulin ratio) was 1.0-1.7. The observed values of this ratio in each experiment are listed in Table II.

Biological Activity of SAPG-INS, SAPM-INS and SAPA-INS Immunoreactivity of the purified SAPG-INS was measured by radioimmunoassay (RIA) and was found to have decreased to $30 \%$ of that for native insulin. To study the relation between the immunoreactivity and the bioactivity, $0.5 \mathrm{U} / \mathrm{kg}$ (volume, $0.3 \mathrm{ml}$ ) of Actrapid MC or SAPG-INS was administered i.v. to rats (unit determined by the immunoreactivity). BGL decreased to $28.4 \%$ of the initial value at 60 min post-injection of SAPG-INS, followed by a gradual increase. When cotrol insulin was adminis- tered, the BGL reached a minimum $(29.4 \%)$ at $60 \mathrm{~min}$ post-injection. This was almost the same as the minimal BGL of SAPG-INS. The minimal BGL of SAPM-INS or SAPA-INS was $27.5 \%$ or $31.8 \%$ of the initial value at 60 min post-injection. From these findings we consider the bioactivities of SAPG-INS, SAPM-INS and SAPA-INS to be similar to their immunoreactivities. Seminoff et al. ${ }^{19)}$ assessed the cross-reactivity in RIA and in vivo biological activity of SAPG-INS and indicated that RIA is a reasonable method to determine glycosylated insulin concentration, both in vitro and in vivo. We used, therefore, doses of monosaccharide-modified insulin derivatives, in which their unit value as measured by RIA was equal to that of control insulin.

TABLE I. Physical Properties of SAPG, SAPM and SAPA

\begin{tabular}{|c|c|c|c|c|c|c|}
\hline \multirow[b]{2}{*}{$\begin{array}{l}\text { Deriva- } \\
\text { tive }\end{array}$} & \multicolumn{3}{|c|}{$\operatorname{IR}\left(\mathrm{cm}^{-1}\right)$} & \multirow{2}{*}{$\begin{array}{c}\text { NMR } \\
\text { Observed } \\
\text { ppm of } \\
\text { spacer } \\
\text { group }\end{array}$} & \multirow[b]{2}{*}{$\begin{array}{c}\text { Yield } \\
(\%)\end{array}$} & \multirow[b]{2}{*}{$\underset{\left({ }^{\circ} \mathrm{C}\right)}{\mathrm{mp}}$} \\
\hline & $\begin{array}{c}\text { Amide I } \\
\text { band }\end{array}$ & $\begin{array}{c}\text { Amide II } \\
\text { band }\end{array}$ & $\begin{array}{c}\text { Carbox- } \\
\text { ylic } \\
v(\mathrm{C}=\mathrm{O})\end{array}$ & & & \\
\hline SAPG & 1670 & 1540 & 1730 & 2.7 & 90.5 & $165-167$ \\
\hline SAPM & 1650 & 1530 & 1710 & 2.7 & 52.0 & - \\
\hline SAPA & 1660 & 1540 & 1700 & 2.6 & 72.1 & $165-168$ \\
\hline
\end{tabular}

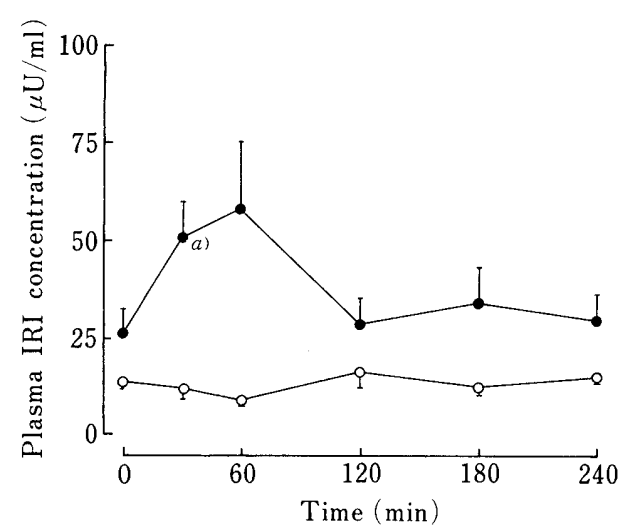

Fig. 1. Changes of IRI Concentration

Blood was collected from the portal $(\Theta)$ or jugular $(O)$ vein after the intraintestinal administration of SAPG-INS $(50 \mathrm{U} / \mathrm{kg}, \mathrm{SAPG} / \mathrm{INS}=1.7)$. Each value represents the mean \pm S.E. of eight experiments. $a$ ) $p<0.05$ compared to the value for $t=0$.

TABLE II. Changes of Blood Glucose Level after the Intestinal Administration of Monosaccharide-Modified Insulin Derivatives

\begin{tabular}{|c|c|c|c|c|c|c|c|c|}
\hline \multirow{3}{*}{ Time (min) } & \multicolumn{8}{|c|}{ Blood glucose level (\%) } \\
\hline & \multicolumn{2}{|c|}{ Native insulin } & \multicolumn{2}{|c|}{ SAPG-INS } & \multicolumn{2}{|c|}{ SAPM-INS } & \multicolumn{2}{|c|}{ SAPA-INS } \\
\hline & $\begin{array}{c}\text { Without b } \\
\text { and pj }\end{array}$ & $\begin{array}{l}\text { With b } \\
\text { and pj }\end{array}$ & $\begin{array}{l}\text { Without b } \\
\text { and pj } \\
\begin{array}{c}\text { SAPG/INS } \\
=1.7\end{array}\end{array}$ & $\begin{array}{c}\text { With b } \\
\text { and pj } \\
\text { SAPG/INS } \\
\quad=1.4\end{array}$ & $\begin{array}{l}\text { Without b } \\
\text { and pj } \\
\text { SAPM/INS } \\
\quad=1.4\end{array}$ & $\begin{array}{c}\text { With b } \\
\text { and pj } \\
\text { SAPM/INS } \\
\quad=1.4\end{array}$ & $\begin{array}{l}\text { Without b } \\
\text { and pj } \\
\text { SAPA/INS } \\
=1.0\end{array}$ & $\begin{array}{c}\text { With b } \\
\text { and pj } \\
\text { SAPA/INS } \\
=1.0\end{array}$ \\
\hline 0 & $100^{c)}$ & $100^{d)}$ & $100^{e)}$ & $100^{f)}$ & $100^{g)}$ & $100^{h)}$ & $100^{i)}$ & $100^{j)}$ \\
\hline 30 & $89.4 \pm 8.4$ & $85.8 \pm 3.6$ & $74.6 \pm 2.0$ & $78.4 \pm 4.8$ & $80.6 \pm 5.8$ & $88.5 \pm 1.7$ & $95.0 \pm 3.2$ & $92.5 \pm 5.0$ \\
\hline 60 & $86.0 \pm 7.5$ & $80.4 \pm 4.3$ & $60.5 \pm 3.8^{b)}$ & $75.0 \pm 6.5$ & $72.2 \pm 4.2$ & $78.4 \pm 1.9$ & $97.0 \pm 5.4$ & $95.3 \pm 6.4$ \\
\hline 120 & $87.1 \pm 8.3$ & $95.6 \pm 7.1$ & $56.0 \pm 6.5^{b)}$ & $71.7 \pm 2.9^{b)}$ & $80.2 \pm 8.4$ & $83.0 \pm 3.9$ & $107.2 \pm 6.9$ & $102.7 \pm 3.5$ \\
\hline 180 & $88.4 \pm 5.7$ & $106.1 \pm 9.3$ & $58.1 \pm 3.8^{a)}$ & $80.6 \pm 5.0^{b)}$ & $84.6 \pm 8.3$ & $84.4 \pm 1.2$ & $119.0 \pm 10.7^{b)}$ & $97.5 \pm 5.1$ \\
\hline 240 & $92.8 \pm 5.3$ & $106.0 \pm 7.7$ & $72.2 \pm 15.9$ & $88.0 \pm 8.0$ & $87.0 \pm 3.7$ & $93.4 \pm 3.5$ & $143.4 \pm 9.3^{a)}$ & $99.4 \pm 12.6$ \\
\hline
\end{tabular}

Each value represents the mean \pm S.E. of four experiments. b: bile, pj: pancreatic juice. $a$ ) $p<0.01$ compared to native insulin, $b$ ) $p<0.05$ compared to native insulin, c) $124.5 \pm 2.8, d) 129.3 \pm 0.9, e) 92.5 \pm 5.1, f) 138.9 \pm 3.9, g) 116.1 \pm 5.4, h) 122.6 \pm 2.1, i) 125.4 \pm 5.8, j) 124.8 \pm 5.4 \mathrm{mg} / \mathrm{dl}$. 
Changes of BGL after the Administration of Actrapid MC, SAPG-INS, SAPM-INS and SAPA-INS The changes in BGL after the administration of glycosylated insulin derivatives in the presence and absence of $\mathrm{b} / \mathrm{pj}$ are shown in Table II. The BGL decreased gradually and reached a minimum $(56 \%$ of the initial value) at $120 \mathrm{~min}$ when SAPG-INS $(50 \mathrm{U} / \mathrm{kg})$ was administered intraintestinally in the absence of $\mathrm{b} / \mathrm{pj}$, while it decreased to only $86 \%$ (at $60 \mathrm{~min}$ ) of the initial value when control insulin was administered. The BGLs between 60 to $180 \mathrm{~min}$ postadministration of SAPG-INS were significantly different from those of the control. The corresponding plasma immunoreactive insulin (IRI) concentration remained at almost the same as the initial levels in blood collected from the jugular vein. In contrast, in blood collected from the portal vein via pyloric vein, the plasma IRI concentration peaked at $58.0 \pm 17.8 \mu \mathrm{U} / \mathrm{ml} 60 \mathrm{~min}$ after administration (Fig. 1). However, the corresponding hypoglycemic effect was not observed. The operation required for cannulation of the pyloric vein caused serious damage to the rats, resulting in an increase of BGL. Therefore, we observed mainly the changes of BGL instead of the simultaneous measurement of BGL and portal IRI in subsequent experiments. In the presence of $b / p j$, administration of the SAPG-INS produced a smaller decrease in BGL (minimum was $71.7 \%$ at $120 \mathrm{~min}$ post-administration). Although the minimal value of BGL after administration of SAPM-INS in the absence of $\mathrm{b} / \mathrm{pj}$ was lower than in the controls, the hypoglycemic effect of SAPM-INS was less marked than that of SAPG-INS. Administration of SAPA-INS produced no hypoglycemic effect either in the absence or presence of $\mathrm{b} / \mathrm{pj}$.

Resistance of Monosaccharide-Modified Insulin to Enzymatic Degradation The Michaelis-Menten parameters $\left(K_{\mathrm{m}}, V_{\max }\right)$ obtained from Lineweaver-Burk plots of enzymatic degradation of SAPG-, SAPM- and SAPA-INS, the metabolic turnover number $\left(k_{\text {cat }}, k_{\text {cat }}=V_{\text {max }} /\left[E_{0}\right]\right)$ and $k_{\text {cat }} / K_{\mathrm{m}}$ are shown in Table III. [ $\left.E_{0}\right]$ is the total enzyme concentration. In either case, the $k_{\text {cat }} / K_{\mathrm{m}}$ value for native insulin was greater than those for SAPG-, SAPM- and SAPA-INS.

The monosaccharide-modified insulin derivatives used in this study were a heterogeneous mixture of mono-, di- and trisubstituted insulin since we could not separate and purify each substituted insulin. Seminoff et $a .^{19)}$ have reported that the bioactivities of B-1 phenylalanine monosubstituted SAPG-INS and A-1 glycine monosubstituted SAPG-INS were comparable to that of native insulin, and that the bioactivity of B-1, A-1 disubstituted SAPG-INS was about $61 \%$ of native insulin. Bioactivity of trisubstituted
SAPG-INS would be lower than, or comparable to, that of the disubstituted insulin. They found that the bioactivity of unseparated SAPG-INS was $21.6 \mathrm{IU} / \mathrm{mg}(86 \%$ of native insulin). In the present study, however, the immunoreactivity of unseparated SAPG-INS was found to be $30 \%$ of native insulin. This low immunoreactivity may be mainly due to the presence of inactive protein fragments rather than a high content of di- or trisubstituted insulin in our preparation. To adjust the dose of monosaccharidesubstituted insulin derivatives to that of control $(50 \mathrm{U} / \mathrm{kg})$, we administered about 3 times as much protein. It was conceivable that differences in amounts of administered protein could affect BGL. To examine this possibility, we administered $150 \mathrm{U} / \mathrm{kg}$ of native insulin intraintestinally to rats. The $\mathrm{BGL}$ reached a minimum $(82.5 \%$ of the initial value) at $1 \mathrm{~h}$ post-administration, which was comparable to that of the control dose. This indicated that hypoglycemic effects were not produced by an increased concentration of insulin.

The increase of IRI concentration was observed only when blood was collected from the portal vein via the pyloric vein (Fig. 1). This finding suggested that the SAPG-INS absorbed intestinally was metabolized by a hepatic first pass-effect. Kaplan and Madison ${ }^{22)}$ reported that on the average about $54 \%$ of intraportally administered insulin was extracted by the liver during a single transhepatic circulation. Sminoff et al. $^{20)}$ demonstrated that more than $85 \%$ of the bovine or SAPG-insulin injected into the portal vein was extracted by the liver in dogs receiving a low heparin dose. Thus, it is desirable to measure the IRI concentration in blood collected from the portal vein to confirm the intestinal absorption of insulin, if the procedure required for blood sampling does not affect the BGL.

There are at least two possible explanations for the hypoglycemic effect of monosaccharide-modified insulin derivatives. First, the increased resistance of insulin to enzymatic degradation as a result of the glycosylation could be a mechanism for the hypoglycemic effect. The $k_{\text {cat }} / K_{\mathrm{m}}$ values shown in Table III indicate that the complementarity between the enzyme and substrate was decreased by glycosylation. The order of magnitude of the $k_{\mathrm{cat}} / K_{\mathrm{m}}$ value, however, did not inversely relate to that of the degree of hypoglycemic effect (SAPG-INS $>$ SAPM-INS $>$ SAPAINS). The changes of insulin conformation by the glycosylation probably diminished the binding ability of the enzyme, increasing the resistance to enzymatic degradation. In regard to resistance to enzymatic degradation, Fujii et $a{ }^{13)}$ reported the promoting effect of chymotrypsin inhibitor on the intestinal absorption of insulin in rats and dogs. Bile salts have a promoting effect on the large-

TABLE III. Kinetic Parameters of Degradation of Insulin Derivatives by Digestive Enzymes

\begin{tabular}{|c|c|c|c|c|c|c|c|c|}
\hline \multirow{2}{*}{ Derivative } & \multicolumn{4}{|c|}{ Chymotrypsin } & \multicolumn{4}{|c|}{ Pepsin } \\
\hline & $\underset{(\mathrm{mM})}{K_{\mathrm{m}}}$ & $\begin{array}{c}V_{\max } \\
(\mu \mathrm{M} / \min )\end{array}$ & $\begin{array}{c}k_{\text {cat }} \\
(1 / \mathrm{min})\end{array}$ & $\begin{array}{c}k_{\text {cat }} / K_{\mathrm{m}} \\
(1 / \mathrm{min} \cdot \mathrm{mM})\end{array}$ & $\begin{array}{c}K_{\mathrm{m}} \\
(\mathrm{mM})\end{array}$ & $\begin{array}{c}V_{\max } \\
(\mu \mathrm{M} / \min )\end{array}$ & $\begin{array}{c}k_{\text {cat }} \\
(1 / \mathrm{min})\end{array}$ & $\begin{array}{c}k_{\text {cat }} / K_{\mathrm{m}} \\
(1 / \mathrm{min} \cdot \mathrm{mM})\end{array}$ \\
\hline Bovine-INS & 0.171 & 6.48 & 2.75 & 16.11 & 0.035 & 3.16 & 1.40 & 39.88 \\
\hline SAPG-INS & 0.484 & 6.87 & 2.92 & 6.03 & 0.123 & 2.85 & 1.26 & 10.23 \\
\hline SAPM-INS & 1.145 & 9.05 & 3.85 & 3.36 & 0.172 & 2.44 & 1.08 & 6.27 \\
\hline SAPA-INS & 0.769 & 15.93 & 6.77 & 8.80 & 0.097 & 1.21 & 0.53 & 5.51 \\
\hline
\end{tabular}

Concentration of chymotrypsin and pepsin were 2.353 and $2.264 \mu \mathrm{M}$, respectively. 
intestinal absorption of insulin. Kidron et $a .^{10)}$ suggested that the absorption of insulin was promoted by the endogenous bile acid present in the small intestine only when insulin was protected against proteolysis. In our experiment, the hypoglycemic effect of SAPG-INS was more evident in the absence of $b / p j$ than in their presence (Table II). The absence of pancreatic juice seems to be more effective on the small-intestinal absorption of SAPG-INS than the promoting effect of bile salts, since the resistance of SAPG-INS to proteolysis, which was obtained by the monosaccharide-modification, may not be as effective as trypsin inhibitor.

Second, the absorption of insulin may be facilitated by its modification with monosaccharides. It is generally accepted that D-pyranose with an equatorial OH-group at $\mathrm{C}_{2}$ position is absorbed in the small intestine by a carrier-mediated active transport mechanism. ${ }^{23}$ ) It was reported that the relative rates of absorption were in the order of D-glucose, D-mannose, D-arabinose. ${ }^{24)}$ In addition, the L-form arabinose used in this study was considered not to be absorbed. It was of interest that the order of hydroglycemic effects of monosaccharide-modified insulin (SAPG-INS $>$ SAPM-INS $>$ SAPA-INS) paralleled the order of intestinal absorption of monosaccharide. Faust reported that the brush border region, including the microvillus core, possesses the capacity to bind D-glucose in preference to D-mannose and L-glucose and that this binding activity is $\mathrm{Na}^{+}$dependent. ${ }^{25}$ ) It is likely that the saccharide attached to insulin enhances interaction with the intestinal wall and increased molecules in close proximity to the wall could lead to increased permeated amounts.

Finally, the two mechanisms described above may contribute jointly to the hypoglycemic effect of monosaccharide-modified insulin derivatives. The hypoglycemic effect of monosaccharide-modified insulin derivatives may be explained in terms of the increased resistance to enzymatic degradation and the increased absorption to the intestinal wall. Further studies on the effect of inhibitors such as phlorizin are under way to investigate whether monosaccharide-carrier interaction contributes to the absorption of monosaccharide-modified insulin.

In the present study we described the small intestinal absorption and hypoglycemic effect of monosaccharidemodified insulin in rats. We confirmed that the resistance of insulin to enzymatic degradation was increased by the modification of insulin with monosaccharide. The absorption mechanism of monosaccharide-modified insulin remains uncertain. Further study employing separated derivatives instead of a heterogeneous mixture is required.

\section{References and Notes}

1) Present address: Drug Delivery Center, Medicinal Research Laboratories, Central Research Laboratories, Yamanouchi Pharmaceutical Co., Ltd., 180 Oozumi, Yaizu-shi 425, Japan.

2) Present address: Oncology Section, Research Laboratories, Nippon Kayaku Co., Ltd., 3-31-12 Shimo, Kita-ku, Tokyo 115, Japan.

3) C. W. Crane, M. C. Path and G. R. W. H. Luntz, Diabetes, 17, 625 (1968).

4) E. Bjork and P. Edman, Int. J. Pharm., 47, 233 (1988).

5) G. S. Gordon, A. C. Moses, R. D. Silver, J. S. Flier and M. C. Carey, Proc. Natl. Acad. Sci. U.S.A., 82, 7419 (1985).

6) J. P. Longenecker, A. C. Moses, J. S. Flier, R. D. Silver, M. C. Carey and E. J. Dubovi, J. Pharm. Sci., 76, 351 (1987).

7) T. Nishihata, M. Sudoh, H. Inagaki, A. Kamada, T. Yagi, R. Kawamori and M. Shichiri, Int. J. Pharm., 38, 83 (1987).

8) T. Nagai and Y. Machida, Pharm. Int., 6, 196 (1985).

9) J. C. Liu, Y. Sun, O. Siddiqui, Y. W. Chien, W. Shi and J. Li, Int. J. Pharm., 44, 197 (1988).

10) M. Kidron, H. Bar-On, E. M. Berry and E. Ziv, Life Sci., 31, 2837 (1982).

11) E. Ziv, M. Kidron, E. M. Berry and H. Bar-On, Life Sci., 29, 803 (1981).

12) H. Yoshikawa, K. Takada and S. Muranishi, J. Pharmcobio-Dyn., 7, 1 (1984).

13) S. Fujii, T. Yokoyama, K. Ikegaya, F. Sato and N. Yokoo, J. Pharm. Pharmacol., 37, 545 (1985).

14) C. Weingarten, A. Moufti, J. Delattre, F. Puisieux and P. Couvreur, Int. J. Pharm., 26, 251 (1985).

15) M. Safran, G. S. Kumar, C. Savariar, J. C. Burnham, F. Williams and D. C. Neckers, Science, 233, 1081 (1986).

16) S. Y. Jeong, S. W. Kim, M. J. D. Eenink and J. Feijen, J. Controlled Rel., 1, 57 (1984).

17) S. Sato, S. Y. Jeong, J. C. McRea and S. W. Kim, J. Controlled Rel., 1, 67 (1984)

18) S. W. Kim, S. Y. Jeong and J. C. McRea, U. S. Patents 4444683; 4478746; 4478830 and 4483792 [Chem. Abstr., 101, 73054 (1984)].

19) L. A. Seminoff, G. B. Olsen and S. W. Kim, Int. J. Pharm., 54, 251 (1989).

20) L. A. Seminoff, J. M. Gleeson, J. Zheng, G. B. Olsen, D. Holmberg, S. F. Mohammad, D. Wilson and S. W. Kim, Int. J. Pharm., 54, 251 (1989).

21) W. Voelter and H. Bauer, J. Chromatogr., 126, 693 (1976).

22) N. Kaplan and L. L. Madison, Clin. Res., 7, 248 (1959).

23) T. H. Wilson, E. C. C. Lin, B. R. Landau and C. R. Jorgensen, Fed. Proc., 19, 870 (1960).

24) R. K. Crane, Physiol. Rev., 40, 789 (1960)

25) R. G. Faust, "Intestinal Absorption and Malabsorption," ed. by T. Z. Csaky, Raven, New York, 1975, p. 155. 